\title{
Thalamic cholinergic innervation is spared in Alzheimer disease compared to Parkinsonian disorders
}

\author{
Vikas Kotagal ${ }^{1}$, Martijn L.T.M. Müller ${ }^{2}$, Daniel I. Kaufer ${ }^{3}$, Robert A. Koeppe ${ }^{2}$, and Nicolaas I. \\ Bohnen ${ }^{1,2,4,5}$ \\ ${ }^{1}$ Department of Neurology, University of Michigan, Ann Arbor, MI \\ ${ }^{2}$ Department of Radiology, Division of Nuclear Medicine, University of Michigan, Ann Arbor, MI \\ ${ }^{3}$ Department of Neurology, University of North Carolina, Chapel Hill, NC \\ ${ }^{4}$ Neurology Service and GRECC, VAAAHS, Ann Arbor, MI \\ ${ }^{5}$ Veterans Administration Pittsburgh Health Care System, Pittsburgh, PA
}

\begin{abstract}
OBJECTIVE-There are two major sources of cholinergic projections in the brain. The nucleus basalis of Meynert provides the principal cholinergic input of the cortical mantle and the pedunculopontine nucleus-laterodorsal tegmental complex (PPN-LDTC; hereafter referred to as PPN) provides the major cholinergic input to the thalamus. Cortical cholinergic denervation has previously been shown to be part of Alzheimer and parkinsonian dementia but there is less information about subcortical thalamic cholinergic denervation. We investigated thalamic cholinergic afferent integrity by measuring PPN-Thalamic (PPN-Thal) acetylcholinesterase (AChE) activity via PET imaging in Alzheimer (AD), Parkinson disease without dementia (PD), Parkinson disease with dementia (PDD) and dementia with Lewy bodies (DLB).
\end{abstract}

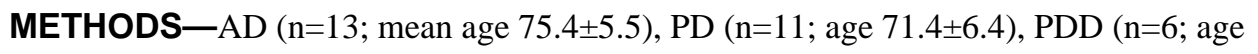
70.8 \pm 4.7 ), DLB ( $\mathrm{n}=6$; age 68.0 \pm 8.6 ) and normal controls (NC; $\mathrm{n}=14$; age 69.0 \pm 7.5 ) subjects underwent $\mathrm{AChE}\left[{ }^{11} \mathrm{C}\right]$-methyl-4-piperidinyl propionate (PMP) PET imaging. PPN-Thal PET data were analyzed using the Nagatsuka method.

RESULTS-There were no significant differences in mean age between the groups ( $\mathrm{F}=1.86$, $\mathrm{p}=0.134)$. Kruskal-Wallis testing demonstrated a significant group effect for PPN-Thal AChE hydrolysis rates $(\mathrm{F}=9.62, \mathrm{P}<0.0001)$. Compared to $\mathrm{NC}$, reduced thalamic $\mathrm{k} 3$ hydrolysis rate was noted in subjects with PDD (-19.8\%; AChE k3 hydrolysis rates $\left.0.1072 \pm 0.0143 \mathrm{~min}^{-1}\right)$, DLB $\left(-17.4 \% ; 0.1103 \pm 0.0112 \mathrm{~min}^{-1}\right)$ and PD $\left(-12.8 \% ; 0.1165 \pm 0.0114 \mathrm{~min}^{-1}\right)$. Each of these 3 subgroups were statistically different from $\mathrm{AD}$ subjects $\left(-0.7 \% ; 0.1326 \pm 0.0095 \mathrm{~min}^{-1}\right)$ who

(C) 2012 Elsevier Ireland Ltd. All rights reserved.

Corresponding author: Vikas Kotagal M.D., 2301 Commonwealth Blvd, Suite 1013, Ann Arbor, MI 48105, Phone (734)-936-9020, Fax (734) 615-4991, vikaskot@med.umich.edu.

Martijn L.T.M. Müller Ph.D., Functional Neuroimaging, Cognitive \& Mobility Laboratory, Domino’s farms, Lobby B-1000, 24 Frank Lloyd Wright Drive, Ann Arbor, MI 48105, mtmuller@umich.edu

Daniel I. Kaufer MD, 3129 POB CB 7025, Chapel Hill, NC 27517, kauferd@neurology.unc.edu

Robert A. Koeppe Ph.D., Division of Nuclear Medicine, University of Michigan, 2276 Med Sci I, SPC 5610, 1301 Catherine Street, Ann Arbor MI 48109-5610, koeppe@umich.edu

Nicolaas I. Bohnen M.D., Ph.D., Functional Neuroimaging, Cognitive \& Mobility Laboratory, Domino’s farms, Lobby B-1000, 24

Frank Lloyd Wright Drive, Ann Arbor, MI 48105, nbohnen@umich.edu

Publisher's Disclaimer: This is a PDF file of an unedited manuscript that has been accepted for publication. As a service to our customers we are providing this early version of the manuscript. The manuscript will undergo copyediting, typesetting, and review of the resulting proof before it is published in its final citable form. Please note that during the production process errors may be discovered which could affect the content, and all legal disclaimers that apply to the journal pertain. 
showed relatively spared thalamic $\mathrm{k} 3$ hydrolysis rates which were comparable to NC $\left(0.1336 \pm 0.0142 \mathrm{~min}^{-1}\right)$.

CONCLUSIONS-Thalamic cholinergic denervation is present in PD, PDD, and DLB but not in AD. Neurodegenerative involvement of thalamic cholinergic afferent projections may contribute to disease-specific motor and cognitive abnormalities.

\section{Keywords}

Acetylcholine; $\left[{ }^{11} \mathrm{C}\right]$ PMP PET; Alzheimer disease; Parkinson disease; PPN; Parkinson disease with dementia

\section{Introduction}

Cortical cholinergic denervation is a well-established pathological hallmark of Alzheimer disease (AD).[7] The two principle cholinergic projection systems of the brain include the basal forebrain system, in particular the nucleus basalis of Meynert (nBM), which supplies cholinergic projections throughout the cerebral cortex and pontine projection system, including the pedunculopontine nucleus (PPN) and the lateral dorsal tegmental nucleus (LDTN), both of which provide cholinergic innervation to various subcortical structures including the basal ganglia, thalamus, brainstem and rostral spinal cord.[10, 20] While loss of $\mathrm{nBM}$ cholinergic neurons is a classic feature of feature of $\mathrm{AD}[26]$, less is known about the integrity of the pontine cholinergic projection system and its role in the pathogenesis of $\mathrm{AD}$.

Though cortical cholinergic changes are recognized as a universal hallmark of late-stage $\mathrm{AD}$, we have previously reported in vivo imaging findings suggesting that cortical cholinergic deficits in mild to moderate AD are less robust in comparison to those seen in Parkinson disease (PD) with dementia (PDD) of comparable severity of dementia.[4] Interestingly, thalamic cholinergic changes have also been described in PD without dementia and may associate with a propensity for falls and REM sleep behavior disorder.[5, 15] As the presence of REM sleep behavior disorder and falls is much more common in PD than in $\mathrm{AD}$, it is possible that these clinical phenotypic differences between these neurodegenerative disorders may reflect differences in the integrity of the cholinergic system.

In vivo $\left[{ }^{11} \mathrm{C}\right]$-methyl-4-piperidinyl propionate (PMP) positron emission tomography (PET) imaging assessment of acetylcholinesterase (AChE) activity in the human brain is a reliable marker for cholinergic terminal integrity[24] and also allows the differential assessment of cortical and subcortical (PPN-Thal) cholinergic systems in vivo. We performed $\left[{ }^{11} \mathrm{C}\right]-\mathrm{PMP}$ PET imaging in subjects with $\mathrm{AD}$ and various alpha-synuclein-related disorders (PD, PDD, and Dementia with Lewy Bodies--DLB) to assess the possible differential role of the pontine cholinergic projection system in these neurodegenerative diseases. We hypothesized that thalamic cholinergic denervation is present in these parkinsonian disorders but not in AD.

\section{Methods}

Subjects

This study involved 50 subjects: 13 with AD, 11 with PD, 6 with PDD, 6 with DLB, and 14 normal controls (NC). Results of the cortical AChE data from these subjects has been published previously.[4] There were no significant differences in mean (SD) age among the groups (table 1): those with $\mathrm{AD}, 75.4$ (5.5) years; those with PD, 71.4 (6.4) years; those with 
PDD, 70.8 (4.7) years; those with DLB, 68.0 (8.6) and NCs, 69.0 (7.5) years; $\mathrm{F}=1.86, P=$ $0.134)$.

Mini-Mental State Examination (MMSE) scores (mean [SD]) were decreased in the groups with dementia with those with AD being 22.1 (5.0); those with PD, 27.2 (2.6); those with PDD, 23.8 (2.6); those with DLB 21.3 (6.7); and NCs, 29.0 (1.6); (F = 8.15, P<.001) but the scoreswere not significantly different between the AD group and PDD/DLB-affected groups $(t=-0.25, P=0.80)$. MMSE scores were not significantly different between those who had PDD and those who had DLB (mean [SD], 23.8 [2.6] and 21.3 [6.6], respectively; $t=0.86, \mathrm{P}$ $=0.41)$. Gender distribution was different among groups: $\mathrm{AD}(8$ women, 4 men $) ; \mathrm{PD}(0$ women, 11 men); PDD (0 women, 6 men); DLB (1 woman, 5 men); NC (4 women, 10 men). The overrepresentation of males in our cohort may reflect both the increased prevalence of Parkinson disease amongst men[3] as well as the relatively male-predominant gender demographics of subjects recruited from the Veteran Affairs Healthcare system. However, previous AChE PET studies in NC did not find AChE-activity gender differences in either cortical or thalamic regions of interest.[16]

AD subjects were diagnosed using the NINCDS-ADRDA (National Institute of Neurological and Communicative Disorders and Stroke-Alzheimer's Disease and Related Disorders Association) criteria. $[2,18]$ PDD was diagnosed in patients having a history of idiopathic PD with incident dementia. DLB was clinically diagnosed following the Consortium on Dementia With Lewy Bodies' criteria.[17] No subjects were taking anticholinergic or cholinesterase inhibitor drugs. Subjects with PD, PDD, and DLB were taking a variable combination of carbidopa-levodopa, selegiline hydrochloride, or dopamine agonists. Dopaminergic medications were withheld for at least 12 to 18 hours (overnight withdrawal) prior to PET imaging the next morning. All NC subjects had a normal neurological examination at the time of the study. This study was approved by the institutional review board and informed consent was obtained for all subjects.

\section{AChE PET AND MAGNETIC RESONANCE IMAGING}

The $\left[{ }^{11} \mathrm{C}\right] \mathrm{PMP}$ radioligand is an acetylcholine analogue that serves as a selective substrate for AChE hydrolysis.[11] The hydrolyzed radioligand becomes trapped as a hydrophilic product locally in the brain following the AChE biodistribution. The $\left[{ }^{11} \mathrm{C}\right] \mathrm{PMP}$ was prepared using a previously described method[25]. Dynamic PET scanning was performed for 80 minutes following a bolus intravenous injection of $15 \mathrm{mCi}(555 \mathrm{MBq})$ of $\left[{ }^{11} \mathrm{C}\right] \mathrm{PMP}$. Sequential emission scans were obtained in 3-dimensional imaging mode using an emission computed axial tomograph (ECAT HR+; CTI PET Systems, Knoxville, Tenn), which acquires 63 transaxial slices (slice thickness, $2.4 \mathrm{~mm}$ with an in-plane resolution of $4.1 \mathrm{~mm}$ ). A thermoplastic mask was made for each subject to minimize head movement. The PET emission data were corrected for attenuation, scatter, and radioactive decay.

A volumetric spoiled-echo gradient recall MRI was collected for each subject using a 1.5-T scanner (Signa; GE Medical Systems, Milwaukee, Wis). The MRI data were cropped in preparation for alignment with the PET data using AnalyzeAVW software (Biomedical Imaging Resource; Mayo Foundation, Rochester, Minn).

\section{DATA ANALYSIS}

All dynamic PET image frames were spatially co-registered within subjects with a rigidbody transformation to reduce the effects of subject motion during the imaging session [22]. Data were co-registered, reoriented, and nonlinearly warped using NeuroStat routines. Thalamic volume-of-interest was determined using an in-house developed brain PET atlas. $[21,22]$ 
$\mathrm{AChE}$ hydrolysis rates $\left(k_{3}\right)$ were estimated using a method using the striatum as the reference input tissue.[23] Mean right \& left thalamic AChE hydrolysis rates were averaged. The Kruskal-Wallis test and post-hoc Wilcoxon rank-sum testing with Bonferonni correction for multiple comparisons were used for statistical group comparison.

\section{Results}

Mean thalamic AChE Activity $\left[{ }^{11} \mathrm{C}\right] \mathrm{PMP} \mathrm{k} 3$ values for all subgroups are shown in table 2 . Kruskal-Wallis testing revealed significant differences between subgroups $\left(\chi^{2}=24.03, p<\right.$ $0.001)$. AD subjects showed relatively preserved thalamic cholinergic innervations compared to subjects with PD, PDD and DLB. Relative to NCs, AD subjects showed only a $0.7 \%$ reduction in thalamic k3 hydrolysis rate. Comparatively, subjects with PD (12.8\%), PDD (19.8\%), and DLB (17.4\%) showed significantly greater thalamic cholinergic denervation relative to both $\mathrm{AD}$ and NCs (Figure 1). Figure 2 depicts subgroup averages for regional mean PMP k3.

Intergroup comparisons were performed using the Wilcoxon rank-sum test with Bonferonni correction (Significant p-value defined as $<0.008$ ). Differences in thalamic $\left[{ }^{11} \mathrm{C}\right]$ PMP k3 were seen between $\mathrm{AD}$ subjects and subjects with $\mathrm{PD}(\mathrm{Z}=-3.071, \mathrm{p}=0.002), \mathrm{PDD}(\mathrm{Z}=$ $-2.982, p=0.003)$ and DLB $(Z=-2.982, p=0.003)$ (table 3$)$. There were no significant differences between AD subjects and NCs $(Z=-0.34, p=0.734)$. Subjects with PDD showed the lowest PMP thalamic hydrolysis rate amongst all subgroups though Wilcoxon rank-sum test did not demonstrate a statistically significant difference between PDD and DLB groups $(Z=-0.641, p=0.522)$. There were no significant differences between the PD versus the PDD/DLB groups $(Z=1.385, \mathrm{p}=0.166)$.

\section{Discussion}

Our in vivo imaging findings suggest that patients with mild AD have similar thalamic cholinergic system integrity compared to normal controls and no significant thalamic cholinergic denervation compared to PD and parkinsonian dementia patients. These findings are consistent with the limited published post-mortem literature on the pontine cholinergic system in AD. Dugger et al. compared postmortem PPN/LDTN findings in subjects with Lewy-body-related disorders (LBD) $(n=19), A D(n=19)$ and normal controls $(n=10)$ and found the PPN and LDTN to be susceptible to Lewy body pathology in LBD and tau pathology in AD. However, only the subjects with Lewy body disorders were found to have significant cell loss relative to normal controls.[8] Woolf et al. found similar results in a smaller postmortem study involving 4 subjects with $\mathrm{AD}$.[27] Brandel et al. found selective loss of subtantia innominata neurons in $\mathrm{AD}$ whereas there was sparing of the brainstem cholinergic neurons.[6]

In animal models of neurodegenerative disorders, impairment of the pontine cholinergic projection system has been associated with a number of motor and non-motor features including sleep disorders and gait imbalance. Janzen $e t$ al. recently demonstrated an association between visual hallucinations in PD and PPN atrophy as assessed by voxel based morphometry.[13] We have recently found an association between symptoms of REM sleep behavior disorder in PD and both cortical and thalamic subcortical cholinergic denervation. [15] We also previously reported on higher incidence of falls in PD related to PPN/Thal cholinergic denervation.[5] As both RBD and falls are not common symptoms in prototypical $\mathrm{AD}$ these clinical phenotypic features may reflect thalamic cholinergic denervation. PPN/LDTN cholinergic denervation may also portend the development of a specific cognitive subtype more analogous to the frontal-subcortical cognitive syndrome seen in early PD that tends to manifest with impaired attention, executive dysfunction, and 
to a lesser extent, visuospatial impairment.[14] This cognitive phenotype may be associated with postural instability and gait difficulties in PD and may auger increased risk of dementia. $[1,12]$

In contrast to the degeneration of the basal forebrain complex in $\mathrm{AD}$, the cholinergic innervation of the striatum (mainly originating from striatal interneurons) and of the thalamus (mainly originating from the brainstem) appears to remain relatively intact.[19] Hence, AD may be best characterized not by general cholinergic neuronal loss but rather by selective cholinergic denervation of the cerebral cortex, most severely in the temporal lobes and in the adjacent paralimbic areas.[9]

Our findings lend credence to the association between alpha-synucleinopathies and subcortical cholinergic dennervation, though they do not provide support for the early involvement of the pontine cholinergic system in AD. Differences in the integrity of subcortical cholinergic networks may reflect differential cell-specific vulnerability to alphasynuclein aggregates vs tau. A limitation of our study is our relatively small sample sizes and skewed gender distriubtion of DLB and PDD subjects. A limitation of the PMP radioligand is that it is not a good tracer to assess striatal AChE activity. We also note that the lack of an assocation in our cross-sectional study does not rule out the possibility of later involvement of the PPN/LDTN in more advanced AD.

\section{Conclusion}

Our findings suggest that the pontine cholinergic projection system may be relatively spared in early AD. Ongoing advances in the functional neuroimaging may allow for further correlative analyses amongst neurodegenerative diseases with shared cognitive symptoms.

\section{Highlights}

The forebrain and subcortical systems are the principle brain cholinergic projection systems

AChE $\left[{ }^{11} \mathrm{C}\right]$-(PMP) PET estimates in vivo integrity of cholinergic terminals

Subcortical cholinergic denervation is relatively spared in Alzheimer disease compared to parkinsonian disorders

Subcortical cholinergic denervation may correlate with specific clinical features in parkinsonian disorders

\section{Abbreviations}

PPN

LDTC

PET

$\left[{ }^{11} \mathrm{C}\right]$ PMP

AD

PD

PDD

DLB pedunculopontine nucleus

laterodorsal tegmental complex

positron emission tomography

$\mathrm{AChE}\left[{ }^{11} \mathrm{C}\right]$-methyl-4-piperidinyl propionate

Alzheimer disease

Parkinson disease

Parkinson Disease with Dementia

Dementia with Lewy Bodies 


\section{Acknowledgments}

Acknowledgements/Funding

Research support was provided by the Department of Veterans Affairs, and by NIH grants NIA AG05133, P01 NS015655, and R01 NS070856.

\section{References}

1. Aarsland D, Bronnick K, Williams-Gray C, Weintraub D, Marder K, Kulisevsky J, Burn D, Barone P, Pagonabarraga J, Allcock L, Santangelo G, Foltynie T, Janvin C, Larsen JP, Barker RA, Emre M. Mild cognitive impairment in Parkinson disease: a multicenter pooled analysis. Neurology. 2010; 75:1062-1069. [PubMed: 20855849]

2. Association, AP. Diagnostic and Statistical Manual of Mental Disorders. Vol. Fourth Edition. Washington, DC: 1994.

3. Baba Y, Putzke JD, Whaley NR, Wszolek ZK, Uitti RJ. Gender and the Parkinson's disease phenotype. J Neurol. 2005; 252:1201-1205. [PubMed: 16151602]

4. Bohnen NI, Kaufer DI, Ivanco LS, Lopresti B, Koeppe RA, Davis JG, Mathis CA, Moore RY, DeKosky ST. Cortical cholinergic function is more severely affected in parkinsonian dementia than in Alzheimer disease: an in vivo positron emission tomographic study. Arch Neurol. 2003; 60:1745-1748. [PubMed: 14676050]

5. Bohnen NI, Muller ML, Koeppe RA, Studenski SA, Kilbourn MA, Frey KA, Albin RL. History of falls in Parkinson disease is associated with reduced cholinergic activity. Neurology. 2009; 73:1670-1676. [PubMed: 19917989]

6. Brandel JP, Hirsch EC, Malessa S, Duyckaerts C, Cervera P, Agid Y. Differential vulnerability of cholinergic projections to the mediodorsal nucleus of the thalamus in senile dementia of Alzheimer type and progressive supranuclear palsy. Neuroscience. 1991; 41:25-31. [PubMed: 2057062]

7. Davies P, Maloney AJ. Selective loss of central cholinergic neurons in Alzheimer's disease. Lancet. 1976; 2:1403. [PubMed: 63862]

8. Dugger BN, Murray ME, Boeve BF, Parisi JE, Benarroch EE, Ferman TJ, Dickson DW. Neuropathological analysis of brainstem cholinergic and catecholaminergic nuclei in relation to REM sleep behaviour disorder. Neuropathol Appl Neurobiol. 2011

9. Geula C, Mesulam MM. Systematic regional variations in the loss of cortical cholinergic fibers in Alzheimer's disease. Cereb Cortex. 1996; 6:165-177. [PubMed: 8670647]

10. Heckers S, Geula C, Mesulam MM. Cholinergic innervation of the human thalamus: dual origin and differential nuclear distribution. J Comp Neurol. 1992; 325:68-82. [PubMed: 1282919]

11. Irie T, Fukushi K, Akimoto Y, Tamagami H, Nozaki T. Design and evaluation of radioactive acetylcholine analogs for mapping brain acetylcholinesterase (AchE) in vivo. Nucl Med Biol. 1994; 21:801-808. [PubMed: 9234329]

12. Janvin CC, Larsen JP, Aarsland D, Hugdahl K. Subtypes of mild cognitive impairment in Parkinson's disease: progression to dementia. Mov Disord. 2006; 21:1343-1349. [PubMed: 16721732]

13. Janzen J, van 't Ent D, Lemstra AW, Berendse HW, Barkhof F, Foncke EM. The pedunculopontine nucleus is related to visual hallucinations in Parkinson's disease: preliminary results of a voxelbased morphometry study. J Neurol. 2011

14. Kehagia AA, Barker RA, Robbins TW. Neuropsychological and clinical heterogeneity of cognitive impairment and dementia in patients with Parkinson's disease. Lancet Neurol. 2010; 9:1200-1213. [PubMed: 20880750]

15. Kotagal V, Albin RL, Muller ML, Koeppe RA, Chervin RD, Frey KA, Bohnen NI. Symptoms of Rapid Eye Movement Sleep Behavior Disorder are Associated with Cholinergic Denervation in Parkinson Disease. Annals of neurology (accepted 12.2.11). 2011 
16. Kuhl DE, Koeppe RA, Minoshima S, Snyder SE, Ficaro EP, Foster NL, Frey KA, Kilbourn MR. In vivo mapping of cerebral acetylcholinesterase activity in aging and Alzheimer's disease. Neurology. 1999; 52:691-699. [PubMed: 10078712]

17. McKeith IG, Perry EK, Perry RH. Report of the second dementia with Lewy body international workshop: diagnosis and treatment. Consortium on Dementia with Lewy Bodies. Neurology. 1999; 53:902-905. [PubMed: 10496243]

18. McKhann G, Drachman D, Folstein M, Katzman R, Price D, Stadlan EM. Clinical diagnosis of Alzheimer's disease: report of the NINCDS-ADRDA Work Group under the auspices of Department of Health and Human Services Task Force on Alzheimer's Disease. Neurology. 1984; 34:939-944. [PubMed: 6610841]

19. Mesulam M. The cholinergic lesion of Alzheimer's disease: pivotal factor or side show? Learn Mem. 2004; 11:43-49. [PubMed: 14747516]

20. Mesulam MM, Geula C, Bothwell MA, Hersh LB. Human reticular formation: cholinergic neurons of the pedunculopontine and laterodorsal tegmental nuclei and some cytochemical comparisons to forebrain cholinergic neurons. J Comp Neurol. 1989; 283:611-633. [PubMed: 2545747]

21. Minoshima S, Koeppe RA, Frey KA, Kuhl DE. Anatomic standardization: linear scaling and nonlinear warping of functional brain images. J Nucl Med. 1994; 35:1528-1537. [PubMed: 8071705]

22. Minoshima S, Koeppe RA, Mintun MA, Berger KL, Taylor SF, Frey KA, Kuhl DE. Automated detection of the intercommissural line for stereotactic localization of functional brain images. $\mathrm{J}$ Nucl Med. 1993; 34:322-329. [PubMed: 8429356]

23. Nagatsuka Si S, Fukushi K, Shinotoh H, Namba H, Iyo M, Tanaka N, Aotsuka A, Ota T, Tanada S, Irie T. Kinetic analysis of [(11)C]MP4A using a high-radioactivity brain region that represents an integrated input function for measurement of cerebral acetylcholinesterase activity without arterial blood sampling. J Cereb Blood Flow Metab. 2001; 21:1354-1366. [PubMed: 11702050]

24. Shute CC, Lewis PR. Electron microscopy of cholinergic terminals and acetylcholinesterasecontaining neurones in the hippocampal formation of the rat. Z Zellforsch Mikrosk Anat. 1966; 69:334-343. [PubMed: 5973099]

25. Snyder SE, Tluczek L, Jewett DM, Nguyen TB, Kuhl DE, Kilbourn MR. Synthesis of 1[11C]methylpiperidin-4-yl propionate ([11C]PMP) for in vivo measurements of acetylcholinesterase activity. Nucl Med Biol. 1998; 25:751-754. [PubMed: 9863562]

26. Whitehouse PJ, Price DL, Struble RG, Clark AW, Coyle JT, Delon MR. Alzheimer's disease and senile dementia: loss of neurons in the basal forebrain. Science. 1982; 215:1237-1239. [PubMed: 7058341]

27. Woolf NJ, Jacobs RW, Butcher LL. The pontomesencephalotegmental cholinergic system does not degenerate in Alzheimer's disease. Neurosci Lett. 1989; 96:277-282. [PubMed: 2717053] 


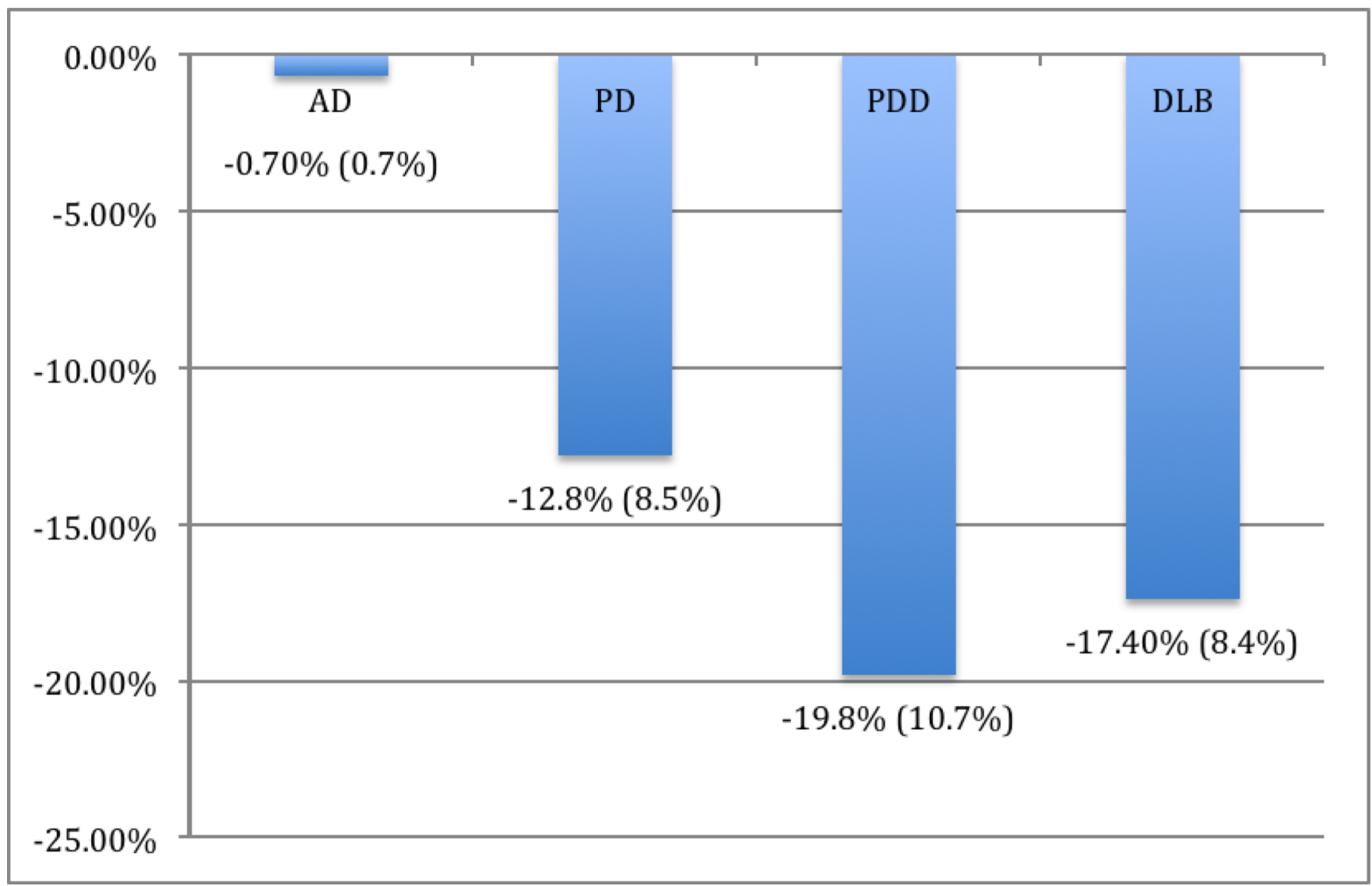

Figure 1.

Relative (\% difference) subcortical cholinergic denervation in Alzheimer disease and alphasynucleinopathies compared to healthy controls. 


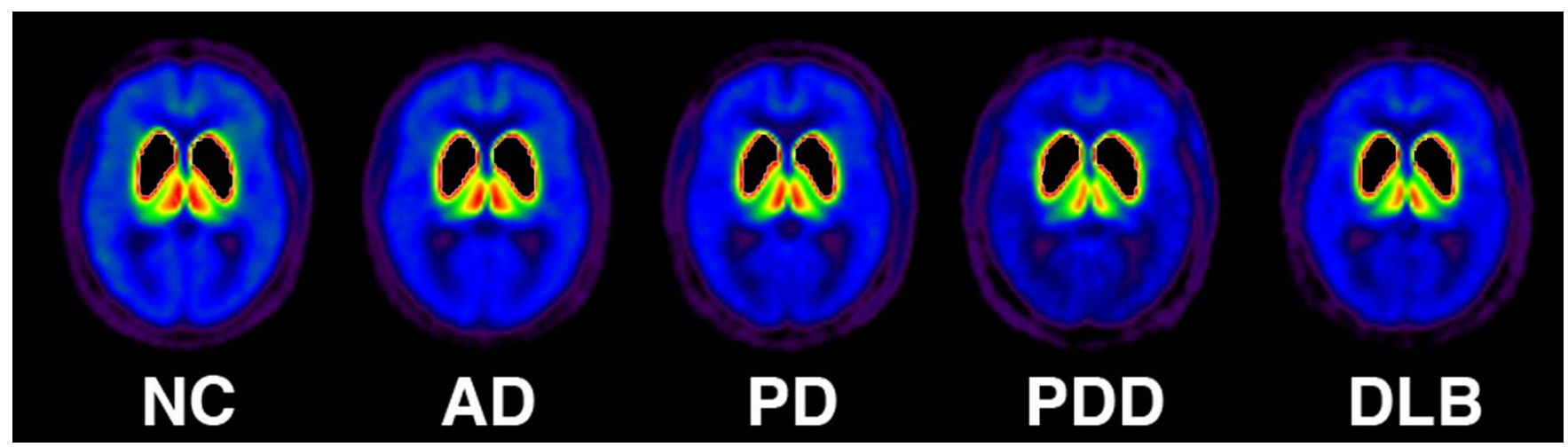

Figure 2.

Legend: $(\mathrm{AD})=$ Alzheimer disease,$(\mathrm{PD})=$ Parkinson disease,$(\mathrm{PDD})=$ Parkinson Disease with Dementia, $(\mathrm{DLB})=$ Dementia with Lewy Bodies 
Table 1

Demographic information

\begin{tabular}{|l|l|l|l|l|l|}
\hline & AD $(\mathbf{n = 1 3})$ & PD $(\mathbf{n = 1 1})$ & PDD $(\mathbf{n = 6})$ & DLB $(\mathbf{n = 6})$ & NC $(\mathbf{n = 1 4})$ \\
\hline Age (SD) & $75.4(5.5)$ & $71.4(6.4)$ & $70.8(4.7)$ & $68.0(8.6)$ & $69.0(7.5)$ \\
\hline MMSE (SD) & $22.1(5.0)$ & $27.2(2.6)$ & $23.8(2.6)$ & $21.3(6.7)$ & $29.0(1.6)$ \\
\hline Gender (F/M) & $(8 / 4)$ & $(0 / 11)$ & $(0 / 6)$ & $(1 / 5)$ & $(4 / 10)$ \\
\hline
\end{tabular}

MMSE $=$ Mini-mental State Exam, $\mathrm{SD}=$ Standard Deviation $(\mathrm{AD})=$ Alzheimer disease,$(\mathrm{PD})=$ Parkinson disease,$(\mathrm{PDD})=$ Parkinson Disease with Dementia, $(\mathrm{DLB})=$ Dementia with Lewy Bodies 


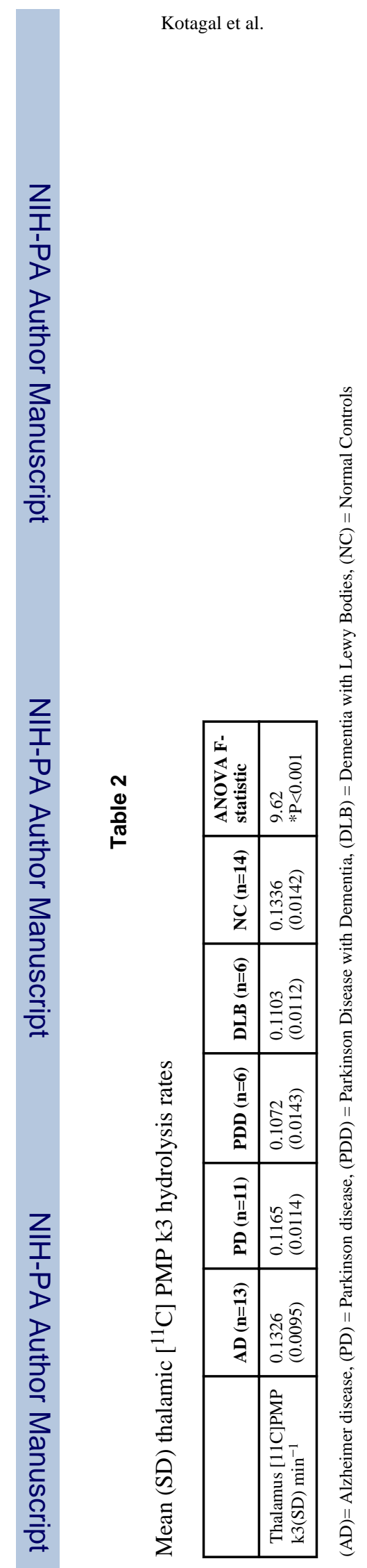

Neurosci Lett. Author manuscript; available in PMC 2013 April 18. 
Table 3

Wilcoxon Rank-Sum test comparing $\left[{ }^{11} \mathrm{C}\right] \mathrm{PMP} \mathrm{k} 3$ hydrolysis rates $\left(\mathrm{min}^{-1}\right)$ in Alzheimer disease compared to other neurodegenerative disorders and normal controls

\begin{tabular}{|l|l|}
\hline & Wilcoxon Rank-Sum test \\
\hline AD vs NC & $z=-0.340, p=0.734$ \\
\hline AD vs DLB & $z=-2.982, p=0.003^{*}$ \\
\hline AD vs PD & $z=-3.071, p=0.002^{*}$ \\
\hline AD vs PDD & $z=-2.982, p=0.003^{*}$ \\
\hline
\end{tabular}

$(\mathrm{AD})=$ Alzheimer disease,$(\mathrm{PD})=$ Parkinson disease,$(\mathrm{PDD})=$ Parkinson Disease with Dementia,$(\mathrm{DLB})=$ Dementia with Lewy Bodies,,$(\mathrm{NC})=$ Normal Controls.

* Statistically significant. Note: p-value for statistical significance $<0.008$ based on Bonferonni correction for multiple comparisons 